AperTO - Archivio Istituzionale Open Access dell'Università di Torino

Microbiota of Milk and Dairy Foods: Structure and Function by -omics Approaches

This is a pre print version of the following article:

Original Citation:

Availability:

This version is available http://hdl.handle.net/2318/1795213

since 2021-07-28T13:27:20Z

Publisher:

ELSEVIER

Published version:

DOI:10.1016/B978-0-08-100596-5.22973-9

Terms of use:

Open Access

Anyone can freely access the full text of works made available as "Open Access". Works made available under a Creative Commons license can be used according to the terms and conditions of said license. Use of all other works requires consent of the right holder (author or publisher) if not exempted from copyright protection by the applicable law. 


\title{
MICROBIOTA of milk and dairy foods: Structure and function by -omics approaches
}

\section{Ilario Ferrocino, Kalliopi Rantsiou and Luca Cocolin}

DISAFA-Agricultural Microbiology and Food Technology Sector, University of Turin, Grugliasco, Torino, Italy

Ilario Ferrocino: ilario.ferrocino@unito.it

Kalliopi Rantsiou kalliopi.rantsiou@unito.it

Luca Cocolin: lucasimone.cocolin@unito.it

Keywords: dairy microbes, food-omics, mycobiota, metagenome, meta-taxonomic, milk microbiome, microbial function, next-generation sequencing, OTUs, omics

\begin{abstract}
In the era of big data we are able to generate billions of individual sequences in order to better identify strains, enzymes or genes in complex food systems, including milk and dairy products. In the last 20 years the number of studies, projects and researchers has increased, trying to discover the microbial complexity in food systems. The -omics technologies that can also be called food-omics techniques (including the study of microbes, genes, proteins and metabolites in food systems) are already widely used to track and map shifts in microbial communities, discover new molecules, new metabolic pathways and also new strains.
\end{abstract}




\section{Introduction}

Food-omics is obtained through several operative steps based on: i) identification of the operational taxonomic units (OTUs) of microbial communities, in terms of density (meta-taxonomic); ii) identification of gene content and genome reconstruction (meta-genomics); iii) identification of the metabolic changes through the description of protein profiling (meta-proteomics); iv) gene function (meta-transcriptomics); v) identification of metabolic changes through the description of metabolite profiling (meta-metabolomics). With this massive application of -omics techniques we are able to obtain, in various ways and by different powerful instruments, a huge amount of data that require computing tools for an in-depth analysis in a reasonable timeframe. But how are we able to integrate data and to decipher what happens in a complex ecosystem like dairy food and how can this information be translated in real life?

The microbiome of milk and its derivatives known as dairy foods is a complex ecosystem susceptible to change due to external perturbations (e.g., temperature, $\mathrm{a}_{\mathrm{w}}, \mathrm{pH}$, ingredients, ambient contamination, transformation process etc.) that have a drastic effect on the final characteristics of the products in terms of organoleptic properties, as well as safety.

Data generated through the food-omics approach can improve the knowledge on what really happens in milk or milk based microbiome.

\section{Metaxonomic approach for microbiota characterization}

Reduced sequencing costs with the advent of user-friendly tools to analyze data have increased the number of research studies on the microbiota composition of various type of milk and their derivatives. Due to their composition rich in proteins, carbohydrates, lipids, vitamins and salts, milk and milk products are a perfect growth substrate for microbes. The microbiota of raw milk includes mainly Gram negative bacteria, Gram positive and catalase positive bacteria, lactic acid bacteria (LAB), yeasts, moulds and bacteriophages (Montel et al., 2014). Main factors that can affect the initial microbial composition are: animal health status (for example mastitis has an important effect on milk microbiota composition), environment (farm, season, temperature etc.) operators, food chain parameters (for example adherence to the cold chain). During the transformation for cheese or yogurt production, the initial microbial composition and the use of a starter culture confer the organoleptic characteristics to the final products. In the last decades, the dairy microbiota has been studied in depth and a flurry of research has aimed to discover the composition of the initial 
microbiota and how this can change across time or fermentation or ripening (De Filippis et al., 2016). The use of a meta-taxonomic approach can help in deciphering the microbial composition since it can be considered as a quantitative approach, even though with such pitfalls as PCR step or operon multicopy of the $16 \mathrm{~S}$ gene (Dolci et al., 2010).

It is well known that the processing environment is one source of microbes that can easily affect the final structure of the microbiota. Equipment, brine tanks and ripening rooms were observed to be the primary source of microbes followed by raw milk, starters, water, air, salt and human skin (Montel et al., 2014). It has been shown that a select taxon may vary depending on the equipment or cheese making process and contribute to the formation of the final microbial community. Microbes from the environment may be adapted and feasibly colonize cheeses (e.g., Lactobacillus casei, Lactobacillus plantarum group) or not (e.g., Actinobacteria) but their distribution is strictly connected with the cheese variety and layer (crust or core) (Calasso et al., 2016).

The use of the meta-taxonomic approach highlights that transport, storage, processing, cleaning and sanitation procedures, time of production (early or later in the day due to a phenomenon of bacterial accumulation; O'Sullivan et al., 2015) can all have an effect in the modification of the dairy microbiota (Kable et al., 2016).

It should be pointed out that most of the research studies use exclusively DNA as target molecule to evaluate the shift in the microbiota due to an external perturbation of the food system. It should be recognized that dead cells can contribute to the microbial composition and can give a distorted vision of the real microbial community and in addition the presence of their associated enzymes can have a significant effect on the final characteristic of the product, even though they are not taken into account.

Such methodology can successfully help in discovering rare taxa involved for example in spoilage. For instance Quigley and colleagues successfully discovered the presence of Thermus, a carotenoid-producing thermophile, in defect-associated cheeses (Quigley et al., 2016).

The study of entire microbial communities by meta-taxonomics has allowed observations regarding microbial interactions. Interestingly, such studies have revealed associations between bacteria that co-occur in a sort of mutualism. For example, cheeses characterized by a high abundance of Streptococcus thermophilus and Lactobacillus rhamnosus were spoiled by Clostridium tyrobutyricum while, when Lactobacillus delbrueckii was most abundant, C. butyricum was the dominant spoiling species (Bassi et al., 2015). It was also shown that LAB (to name a few Streptococcus and Lactobacillus) colonizing the environment could have a valuable effect towards the protection of the dairy products against spoilage bacteria, due probably to competition 
mechanisms (Stellato et al., 2015). The same trend was observed when the natural microbiota of raw milk was dominated by the presence of natural starter culture, like Lb. delbrueckii, Lactobacillus helveticus, and Lb. casei group, that co-exclude spoilage and other contaminant taxa (Alessandria et al., 2016).

A promising area not often studied is the use of alternative genes to be amplified that could allow strain detection and typing. Occurrence of species-specific genes with sequence heterogeneity can be a valid premise to apply high-throughput sequencing strategies and achieve strain specific monitoring, as the cases of the lacS gene for the tracking of $S$. thermophilus (De Filippis et al., 2014) or the use of $\operatorname{slpH}$ locus to assess the biodiversity of the Lb. helveticus strains present in fermented dairy foods (Moser et al., 2017).

\section{Forgotten mycobiota in dairy environment}

In the ecology of milk and dairy products, yeasts and molds, also called mycobiota, are still understudied (Figure 1), probably because the possible use of alternative marker genes (unlike 16S rRNA for bacteria) makes it difficult to compare data or adopt a meta-analysis on different datasets. Most of the researchers used ITS, 18S or D1-D2 domain of the 26S (De Filippis et al., 2017; MotaGutierrez et al., 2019). Another issue is the incomplete databases used for the taxonomy. An example of this pitfall is an underestimation or even complete exclusion of Dekkera custersiana (also known as Brettanomyces custersianus), an important yeast of Kefir beverage, that was included in the Kraken database, while it was absent in the MetaPhlAn2 database (Verce et al., 2019). Mycobiota of cheese products is particularly important on the cheese surface where oxygen is more readily available compared to the core. The most frequently species detected by culturebased approach belong to the genera Candida, Trichosporon, Pichia, Saccharomyces, Rhodotorula, Yarrowia and Kluyveromyces (Montel et al., 2014). Filamentous fungi are also unexplored in cheese and they are an important source of proteolytic and lipolytic enzymes that play an important role during ripening and maturation. The mycobiota of milk and dairy products is a source of metabolites and enzymes that drastically affect the final characteristics of the products. In addition, it should be noted that yeast-yeast and especially yeast-bacteria interactions may affect the establishment of the cheese surface community. An example of this interaction came from the study of Kefir beverage where the exopolysaccharide structure (kefiran), which is mainly produced by Lactobacillus kefiranofaciens, protects and serves as a natural encapsulation material for yeasts like Naumovozyma spp., Kluyveromyces marxianus and Kazachastania khefir (Korsak et al., 2015). One of the ecological niches of the dairy mycobiota is the brine, where Debaryomyces and Candida- 
related species often find their perfect environment (Vermote et al., 2018). Debaryomyces yeasts together with Geotrichum candidum, Penicillium and Aspergillus fungi are frequently detected in milk or dairy products because they are very tolerant to high-salt and low-pH conditions (Almeida et al., 2014; Bertuzzi et al., 2018; Decontardi et al., 2018). Particularly important is their ability in the deacidification of cheese surfaces mediated by the lactate metabolism and consequent production of alkaline metabolites (Schornsteiner et al., 2014). In addition, these microbes are involved in the breakdown of proteins and amino acids with the consequence of producing ammonia that significantly contributes to increasing the $\mathrm{pH}$ of the cheese rind and confers a flavour attribute without having toxic effects (Monnet et al., 2016).

Presence in cheese or milk of uncommon fungi belonging to Alternaria, Davidiella, Cladospoium, Botryotinia and Lodderomyces (Bokulich et al., 2015) probably coming from the environment (air, dust, wood or water) was shown to alter the sensory profiles of products through proteolytic and lipolytic activities with the production of alcohols, organic acids and $\mathrm{CO}_{2}$. The importance of providing new insight on the study of dairy mycobiota is also related to the potential risk associated with fungal contamination, in particular with the exponentially increasing risk of mycotoxin contamination in cheese products (Decontardi et al., 2018; Ramos-Pereira et al., 2019).

The interaction among bacteria and fungi is also of great interest because several bacteria (like Corynebacterium, Halomonas, Pseudomonas, Pseudoalteromonas and Vibrio) are not able to grow in the absence of certain fungi or are inhibited by their presence (like Staphylococcus, Arthrobacter, Brevibacterium, Brachybacterium and Serratia) (Wolfe et al., 2014).

$<$ Figure 1 near here>

Figure 1- Factors influencing the study of dairy mycobiome

\section{Deeply understanding changes in genomic features}

Understanding the metabolic interactions regulating microbial development in complex environments, like dairy products, is the new frontier of the food-omics approach. The use of DNA or RNA shotgun sequencing is increasing its importance in trying to understand what really happens in foods and to find possible biomarkers (genes related to a specific metabolic activity or associated to a specific strain) Figure 2.

<Figure 2 near here>

Figure 1- Representation of shotgun sequencing applications for the study of dairy microbiota or microbiome. 
Through this approach, it is possible to investigate the metabolic potential of the resident microbes and to show how external perturbations of the system (presence of contaminants, process parameters or presence of starter culture) impact cheese ripening, safety and especially flavor development (De Filippis et al., 2018). By the application of RNA based shotgun sequencing it was possible to clarify the link between ripening temperature and gene expression, with a clear correlation with the metabolomic profiles, or discover how fungi are important in the breakdown of lipids and proteins during ripening (De Filippis et al., 2016; Lessard et al., 2014). The application of PCR free sequencing can overcome the limitation of the classical plate count. Traditional culturebased detection methods employed by the dairy industry have limitations with respect to their sensitivity and specificity (McHugh et al., 2018). Low numbers of cells or damaged ones cannot be cultured on the classical plate media. It was also shown that by the use of serial dilutions techniques not all populations can be cultured but only the dominant ones (Wolfe et al., 2014). Additionally, another promising applications of the DNA based, PCR-free shotgun approach, is the resolution of individual strains. Metagenomic sequencing can help in the characterization of enrichment microbiota dynamics and in the identification of competitive species that co-occur during enrichment (Ottesen et al., 2016).

Phenotypic characteristics or specific functions vary substantially not only between different microbial species, but also among different strains of a species (Casaburi et al., 2011; Ercolini et al., 2010; Mu et al., 2019). Presence or absence of a complete set of genes or of specific genes, and their level of sequence homology, allows also to confirm characteristics of particular strains (Almeida et al., 2014). Deeply understanding changes in genomic features between strains belonging to the same species in foods will give the ability to easily modulate specific strains in processing conditions. By this new knowledge we can have the possibility for example to control the dynamics and conditions necessary to modulate proteolytic or lipolytic activity and obtain a desired cheese aroma (Ercolini, 2016). The importance of this technique should be highlighted not only in the study of the microbial dynamics for organoleptic or technological purposes, but also in the light of risk assessment in the dairy food chain. The application of strain tracking can help in identifying the persistence of spore forming bacteria strains in the processing facility or in tracking transient ones. Due to the sensitivity of this approach, new guidelines and standards may need to be introduced to mitigate the risks associated with detection of low-level contamination (McHugh et al., 2018).

The advent of new bioinformatic pipelines to assess strain diversity is becoming more popular since 2016 by the use of new software like MetaMLST (Zolfo et al., 2017), StrainPhlAn (Asnicar et al., 2017), and PanPhlAn (Scholz et al., 2016) that have the advantage to perform a 
comparison of the single-nucleotide polymorphism (SNP) profiles without the need of genome assembly, being faster and less intensive computationally. The faster approach makes them more relevant to real-life scenarios that require rapid testing of several samples (Martin et al., 2017). In this light, these tools can be promising for detection of pathogenic strains, after a short enrichment step in the dairy industry or for epidemiologic studies in order to try to identify outbreak-associated foodborne pathogens by a simple comparison of the single-nucleotide polymorphism (SNP) profiles of outbreak strain genomes versus non outbreak strains (Martin et al., 2017).

This approach can gain popularity not only in studying bacteria but also in analyzing viruses and specifically phages that have a substantial impact in the dairy environment due to their role in modulating the abundance of microbial populations, which may lead to serious problems in production by causing failures in the fermentation process. It was recently shown in a study of the metagenome of airborne viral population in a dairy farm that bacteriophages have the disadvantage to be involved in the mobilization of antimicrobial resistance genes among bacterial populations (Colombo et al., 2018). A shotgun metagenomics analysis of viromes highlighted a high complexity of the viral communities both in terms of viral taxonomy and phage-host associations and showed also that phages can likely act as vectors for horizontal gene transfer (Somerville et al., 2019).

\section{Conclusion}

Several tools and bioinformatics pipelines are available to understand what happens in a dairy ecosystem. Studying the interaction, function and diversity in milk- or cheese- associated microbial communities can be considered a key factor in the dairy industry. Few examples of multi-omics approaches are available in the literature and these approaches need to be implemented. Understanding role, origin, diversity and function of each of the microbial species harbored in this complex systems can increase the knowledge with several field of applications in dairy industry.

\section{References}

Alessandria, V., Ferrocino, I., De Filippis, F., Fontana, M., Rantsiou, K., Ercolini, D., Cocolin, L., 2016. Microbiota of an italian grana-like cheese during manufacture and ripening, unraveled by 16S Rna-based approaches. Appl. Environ. Microbiol. 82, 3988-3995.

Almeida, M., Hébert, A., Abraham, A.L., Rasmussen, S., Monnet, C., Pons, N., Delbès, C., Loux, V., Batto, J.M., Leonard, P., Kennedy, S., Ehrlich, S.D., Pop, M., Montel, M.C., Irlinger, F., Renault, P., 2014. Construction of a dairy microbial genome catalog opens new perspectives 
for the metagenomic analysis of dairy fermented products. BMC Genomics 15 .

Asnicar, F., Manara, S., Zolfo, M., Truong, D.T., Scholz, M., Armanini, F., Ferretti, P., Gorfer, V., Pedrotti, A., Tett, A., Segata, N., 2017. Studying vertical microbiome transmission from mothers to infants by strain-level metagenomic profiling. mSystems 2, 1-13.

Bassi, D., Puglisi, E., Cocconcelli, P.S., 2015. Understanding the bacterial communities of hard cheese with blowing defect. Food Microbiol. 52, 106-118.

Bertuzzi, A.S., Walsh, A.M., Sheehan, J.J., Cotter, P.D., Crispie, F., McSweeney, P.L.H., Kilcawley, K.N., Rea, M.C., 2018. Omics-based insights into flavor development and microbial succession within surface-ripened cheese. mSystems 3: e00211-17.

Bokulich, N.A., Amiranashvili, L., Chitchyan, K., Ghazanchyan, N., Darbinyan, K., Gagelidze, N., Sadunishvili, T., Goginyan, V., Kvesitadze, G., Torok, T., Mills, D.A., 2015. Microbial biogeography of the transnational fermented milk matsoni. Food Microbiol. 50, 12-19.

Calasso, M., Ercolini, D., Mancini, L., Stellato, G., Minervini, F., Di Cagno, R., De Angelis, M., Gobbetti, M., 2016. Relationships among house, rind and core microbiotas during manufacture of traditional Italian cheeses at the same dairy plant. Food Microbiol. 54, 115-126.

Casaburi, A., Nasi, A., Ferrocino, I., Di Monaco, R., Mauriello, G., Villani, F., Ercolini, D., 2011. Spoilage-related activity of Carnobacterium maltaromaticum strains in air-stored and vacuumpacked meat. Appl. Environ. Microbiol. 77(20):7382

Colombo, S., Arioli, S., Gargari, G., Neri, E., Della Scala, G., Mora, D., 2018. Characterization of airborne viromes in cheese production plants. J. Appl. Microbiol. 125, 1444-1454.

De Filippis, F., Genovese, A., Ferranti, P., Gilbert, J.A., Ercolini, D., 2016. Metatranscriptomics reveals temperature-driven functional changes in microbiome impacting cheese maturation rate. Sci. Rep. 6, 1-12.

De Filippis, F., La Storia, A., Stellato, G., Gatti, M., Ercolini, D., 2014. A selected core microbiome drives the early stages of three popular italian cheese manufactures. PLoS One 9, e89680.

De Filippis, F., Laiola, M., Blaiotta, G., Ercolini, D., 2017. Different amplicon targets for sequencing-based studies of fungal diversity 83, 1-9.

De Filippis, F., Parente, E., Ercolini, D., 2018. Recent past , present , and future of the food microbiome. Annu. Rev. Food Sci. Technol. 9, 25.1-25.20.

Decontardi, S., Soares, C., Lima, N., Battilani, P., 2018. Polyphasic identification of Penicillia and Aspergilli isolated from Italian grana cheese. Food Microbiol. 73, 137-149.

Dolci, P., Alessandria, V., Rantsiou, K., Bertolino, M., Cocolin, L., 2010. Microbial diversity, dynamics and activity throughout manufacturing and ripening of Castelmagno PDO cheese. Int. J. Food Microbiol. 143, 71-5. 
Ercolini, D., 2016. Exciting strain-level resolution studies of the food microbiome. Microb. Biotechnol. 10, 54-56.

Ercolini, D., Casaburi, A., Nasi, A., Ferrocino, I., Di Monaco, R., Ferranti, P., Mauriello, G., Villani, F., 2010. Different molecular types of Pseudomonas fragi have the same overall behaviour as meat spoilers. Int. J. Food Microbiol. 142, 120-131.

De Filippis, F., Parente, E., Ercolini, D., 2016. Metagenomics insights into food fermentations. Microbial Biotechnology (2016) 0(0), 000-000

Kable, M.E., Srisengfa, Y., Laird, M., Zaragoza, J., McLeod, J., Heidenreich, J., Marco, M.L., 2016. The core and seasonal microbiota of raw bovine milk in tanker trucks and the impact of transfer to a milk processing facility. MBio 7, 1-13.

Korsak, N., Taminiau, B., Leclercq, M., Nezer, C., Crevecoeur, S., Ferauche, C., Detry, E., Delcenserie, V., Daube, G., 2015. Evaluation of the microbiota of kefir samples using metagenetic analysis targeting the $16 \mathrm{~S}$ and $26 \mathrm{~S}$ ribosomal DNA fragments. J. Dairy Sci. 98 , 3684-3689.

Lessard, M.-H., Viel, C., Boyle, B., St-Gelais, D., Labrie, S., 2014. Metatranscriptome analysis of fungal strains Penicillium camemberti and Geotrichum candidum reveal cheese matrix breakdown and potential development of sensory properties of ripened Camembert-type cheese. BMC Genomics 15, 235.

Walsh A.M., Crispie F., Daari K., O'Sullivan O., Martin J.C., Arthur C.T., Claesson M.J., Scott K.P., Cotter P.D. 2017. Strain-level metagenomic analysis of the fermented dairy beverage nunu. Appl. Environ. Microbiol. 83, 1-13.

McHugh, A.J., Feehily, C., Tobin, J.T., Fenelon, M.A., Hill, C., Cotter, P.D., 2018. Mesophilic sporeformers identified in whey powder by using shotgun metagenomic sequencing. Appl. Environ. Microbiol. 84, 1-14.

Monnet, C., Dugat-Bony, E., Swennen, D., Beckerich, J.-M., Irlinger, F., Fraud, S., Bonnarme, P., 2016. Investigation of the activity of the microorganisms in a reblochon-style cheese by metatranscriptomic analysis. Front. Microbiol. 7, 536.

Montel, M.-C., Buchin, S., Mallet, A., Delbes-Paus, C., Vuitton, D. a, Desmasures, N., Berthier, F., 2014. Traditional cheeses: Rich and diverse microbiota with associated benefits. Int. J. Food Microbiol. 177, 136-154.

Moser, A., Wüthrich, D., Bruggmann, R., Eugster-Meier, E., Meile, L., Irmler, S., 2017. Amplicon sequencing of the slpH locus permits culture-independent strain typing of Lactobacillus helveticus in dairy products. Front. Microbiol. 8, 1-11.

Mota-Gutierrez, J., Ferrocino, I., Rantsiou, K., Cocolin, L., 2019. Metataxonomic comparison 
between internal transcribed spacer and 26S ribosomal large subunit (LSU) rDNA gene. Int. J. Food Microbiol. 290, 132-140.

Mu, A., Kwong, J.C., Isles, N.S., Gonçalves da Silva, A., Schultz, M.B., Ballard, S.A., Lane, C.R., Carter, G.P., Williamson, D.A., Seemann, T., Stinear, T.P., Howden, B.P., 2019.

Reconstruction of the genomes of drug-resistant pathogens for outbreak investigation through metagenomic sequencing. mSphere 4, 1-13.

O’Sullivan, D.J., Cotter, P.D., O’Sullivan, O., Giblin, L., McSweeney, P.L.H., Sheehan, J.J., 2015.

Temporal and spatial differences in microbial composition during the manufacture of a continental-type cheese. Appl. Environ. Microbiol. 81, 2525-2533.

Ottesen, A., Ramachandran, P., Reed, E., White, J.R., Hasan, N., Subramanian, P., Ryan, G., Jarvis, K., Grim, C., Daquiqan, N., Hanes, D., Allard, M., Colwell, R., Brown, E., Chen, Y., 2016. Enrichment dynamics of Listeria monocytogenes and the associated microbiome from naturally contaminated ice cream linked to a listeriosis outbreak. BMC Microbiol. 16, 1-11. Quigley, L., O’Sullivan, D.J., Daly, D., O’Sullivan, O., Burdikova, Z., Vana, R., Beresford, T.P., Ross, R.P., Fitzgerald, G.F., McSweeney, P.L.H., Giblin, L., Sheehan, J.J., Cotter, P.D., 2016. Thermus and the pink discoloration defect in cheese . mSystems 1, 1-12.

Ramos-Pereira, J., Mareze, J., Patrinou, E., Santos, J.A., López-Díaz, T.M., 2019. Polyphasic identification of Penicillium spp. isolated from Spanish semi-hard ripened cheeses. Food Microbiol. 84, 103253.

Scholz, M., Ward, D. V, Pasolli, E., Tolio, T., Zolfo, M., Asnicar, F., Truong, D.T., Tett, A., Morrow, A.L., Segata, N., 2016. Strain-level microbial epidemiology and population genomics from shotgun metagenomics. Nat. Methods 13, 435-438.

Schornsteiner, E., Mann, E., Bereuter, O., Wagner, M., Schmitz-Esser, S., 2014. Cultivationindependent analysis of microbial communities on Austrian raw milk hard cheese rinds. Int. J. Food Microbiol. 180, 88-97.

Somerville, V., Lutz, S., Schmid, M., Frei, D., Moser, A., Irmler, S., Frey, J.E., Ahrens, C.H., 2019. Long-read based de novo assembly of low-complexity metagenome samples results in finished genomes and reveals insights into strain diversity and an active phage system. BMC Microbiol. $19,1-18$.

Stellato, G., De Filippis, F., La Storia, A., Ercolini, D., 2015. Coexistence of lactic acid bacteria and potential spoilage microbiota in a dairyprocessing environment. Appl. Environ. Microbiol. 81, 7893-7904.

Verce, M., De Vuyst, L., Weckx, S., 2019. Shotgun metagenomics of a water kefir fermentation ecosystem reveals a novel Oenococcus species. Front. Microbiol. 10, 1-16. 
Vermote, L., Verce, M., De Vuyst, L., Weckx, S., 2018. Amplicon and shotgun metagenomic sequencing indicates that microbial ecosystems present in cheese brines reflect environmental inoculation during the cheese production process. Int. Dairy J. 87, 44-53.

Wolfe, B.E., Button, J.E., Santarelli, M., Dutton, R.J., 2014. Cheese rind communities provide tractable systems for in situ and in vitro studies of microbial diversity. Cell 158, 422-433.

Zolfo, M., Tett, A., Jousson, O., Donati, C., Segata, N., 2017. MetaMLST: Multi-locus strain-level bacterial typing from metagenomic samples. Nucleic Acids Res. 45, e7.

\section{Further Reading}

Anelli, P., Peterson, S.W., Haidukowski, M., Logrieco, A.F., Moretti, A., Epifani, F., Susca, A., 2018. Penicillium gravinicasei, a new species isolated from cave cheese in Apulia, Italy. Int. J. Food Microbiol. 282, 66-70.

Buehler, A.J., Evanowski, R.L., Martin, N.H., Boor, K.J., Wiedmann, M., 2017. Internal transcribed spacer (ITS) sequencing reveals considerable fungal diversity in dairy products. J. Dairy Sci. $100,8814-8825$.

Ferranti, P., 2018. The future of analytical chemistry in foodomics. Curr. Opin. Food Sci. 22, 102108.

Ferrocino, I., Cocolin, L., 2017. Current perspectives in food-based studies exploiting multi-omics approaches. Curr. Opin. Food Sci. 13, 10-15.

Levante, A., De Filippis, F., La Storia, A., Gatti, M., Neviani, E., Ercolini, D., Lazzi, C., 2017. Metabolic gene-targeted monitoring of non-starter lactic acid bacteria during cheese ripening. Int. J. Food Microbiol.

Murugesan, S., Reyes-Mata, M.P., Nirmalkar, K., Chavez-Carbajal, A., Juárez-Hernández, J.I., Torres-Gómez, R.E., Piña-Escobedo, A., Maya, O., Hoyo-Vadillo, C., Ramos-Ramírez, E.G., Salazar-Montoya, J.A., García-Mena, J., 2018. Profiling of bacterial and fungal communities of Mexican cheeses by high throughput DNA sequencing. Food Res. Int. 113, 371-381.

Parente, E., Cocolin, L., De Filippis, F., Zotta, T., Ferrocino, I., O’Sullivan, O., Neviani, E., De Angelis, M., Cotter, P.D. Ercolini, D., 2016. FoodMicrobionet: A database for the visualisation and exploration of food bacterial communities based on network analysis. Int. J. Food Microbiol. 219, 28-37. 
Ropars, J., Rodríguez De La Vega, R.C., López-Villavicencio, M., Gouzy, J., Sallet, E., Dumas, É., Lacoste, S., Debuchy, R., Dupont, J., Branca, A., Giraud, T., 2015. Adaptive horizontal gene transfers between multiple cheese-associated fungi. Curr. Biol. 25, 2562-2569.

Soggiu, A., Piras, C., Mortera, S.L., Alloggio, I., Urbani, A., Bonizzi, L., Roncada, P., 2015.

Unravelling the effect of clostridia spores and lysozyme on microbiota dynamics in Grana

Padano cheese: A metaproteomics approach. J. Proteomics 147, 21-27.

Tilocca, B., Costanzo, N., Morittu, V.M., Spina, A.A., Soggiu, A., Britti, D., Roncada, P., Piras, C., 2020. Milk microbiota: Characterization methods and role in cheese production. J. Proteomics 210,103534

Figure1

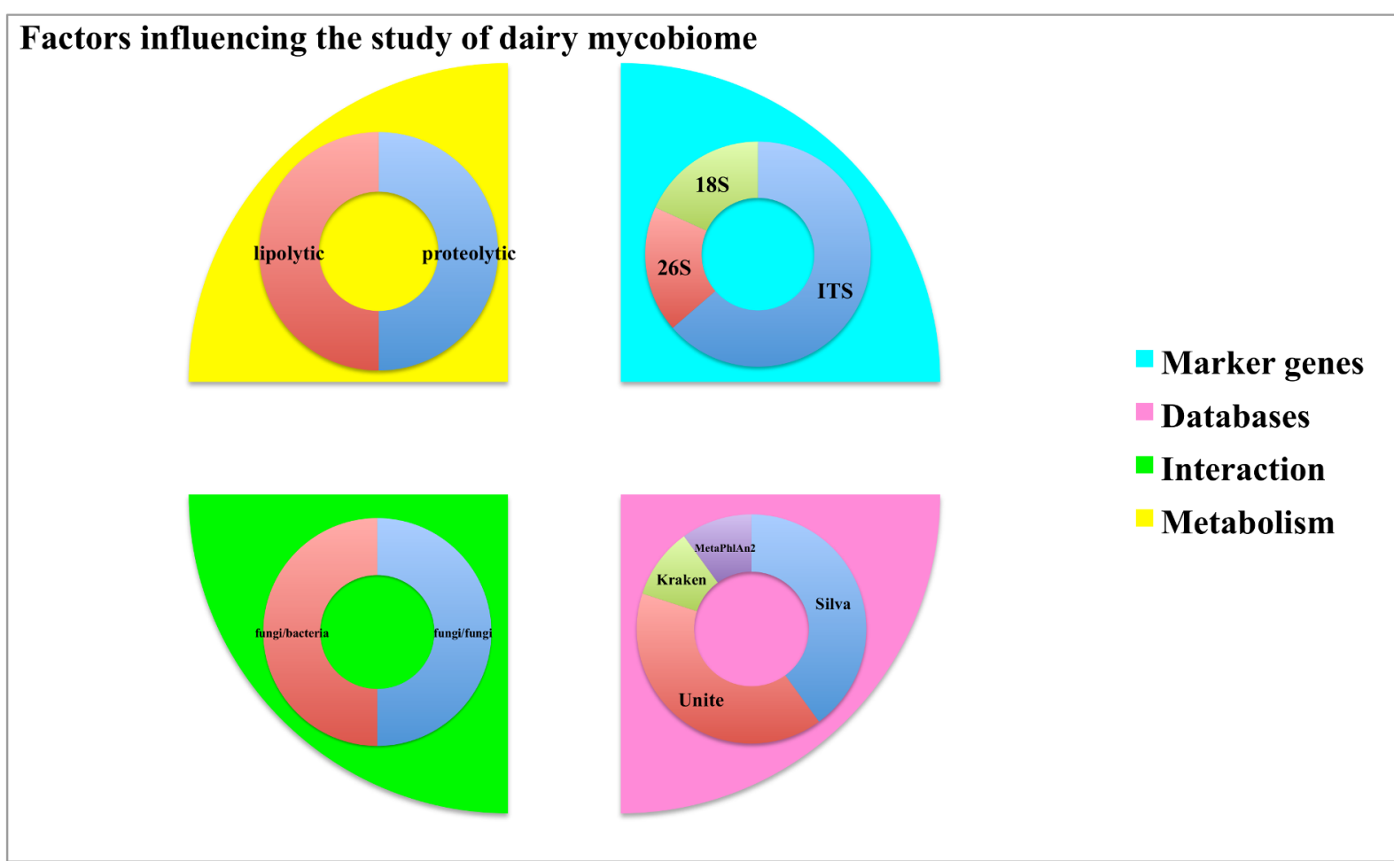



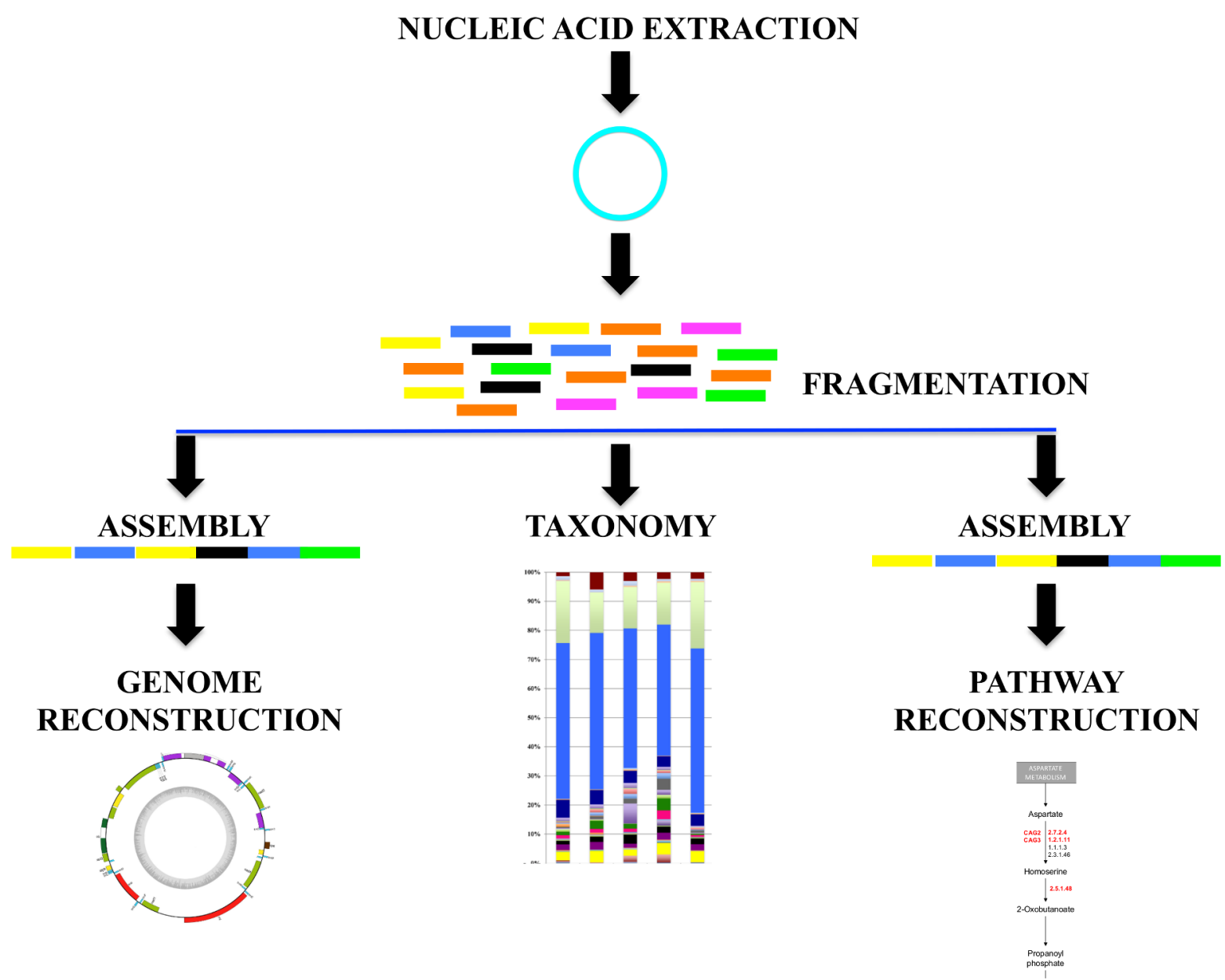